\title{
A Case of Diffuse Metastatic Melanoma With Massive Spontaneous Hemoperitoneum
}

\author{
Jamin K. Addae ${ }^{1}$, Robert D. Rawlinson ${ }^{2}$, Abigail Adjei ${ }^{3}$, Bruce Brenner ${ }^{2}$, Karin Blumofe ${ }^{1}$ \\ 1. General Surgery, Charles E. Schmidt College of Medicine, Florida Atlantic University, Boca Raton, USA 2. Surgery, \\ Charles E. Schmidt College of Medicine, Florida Atlantic University, Boca Raton, USA 3. Epidemiology and Public \\ Health, Health Science Center at Houston, University of Texas, Austin, USA
}

Corresponding author: Jamin K. Addae, jaminaddae@gmail.com

\begin{abstract}
The incidence rate for melanoma continues to rise in the USA. The majority of melanoma cases are detected at an early stage and are amenable to surgical excision. Advanced melanoma with diffuse intraabdominal metastasis is rare. We present a case of a 50-year-old female with no known primary or history of melanoma who presented with massive intraabdominal bleeding secondary to diffuse metastatic melanoma with peritoneal implants. Diagnosing metastatic melanoma could be challenging. Clinicians should be aware of hemoperitoneum or peritoneal carcinomatosis as potential manifestations of malignant melanoma to expedite appropriate management.
\end{abstract}

Categories: Dermatology, General Surgery, Oncology

Keywords: melanoma, hemoperitoneum, diffuse metastatic melanoma, skin cancer, occult melanoma

\section{Introduction}

Melanoma is the fifth most common cause of cancer in both men and women in the USA [1]. The majority of cases are diagnosed at an early stage where surgical excision alone is often curative [2, 3]. Advanced cases may require immunotherapy, targeted therapy, chemotherapy, or radiation therapy in addition to surgical excision [4].

Cutaneous melanoma may regress spontaneously without any surgical intervention. Metastatic disease can be challenging to diagnose in these cases when there is no known primary [5]. Patients with mucosal or ocular melanoma may also present with metastases prior to developing symptoms from the primary tumor. We present a rare case of a patient with massive hemoperitoneum as a complication of peritoneal deposits of melanoma without a known primary.

Received 05/04/2020 Review began 05/27/2020 Review ended 06/06/2020 Published 06/10/2020

๑) Copyright 2020

Addae et al. This is an open access article distributed under the terms of the Creative Commons Attribution License CC-BY 4.0., which permits unrestricted use, distribution, and reproduction in any medium, provided the original author and source are credited.

\section{Case Presentation}

A 50-year-old woman presented with a four-day history of the left flank and lower abdominal pain. Her pain worsened with positional changes and waxed and waned. She reported nausea and abdominal distension, but no emesis, fever, or chills. She denied any urinary symptoms, hematemesis, bleeding per rectum, or use of any anticoagulants. Her past medical history was unremarkable. Her last Papanicolau (Pap) smear was nine years ago and was normal. Her past surgical history was significant for rhinoplasty and breast augmentation.

On admission, she was tachycardic, but not febrile or hypotensive. On physical examination, she was found to be pale with a distended abdomen and generalized abdominal tenderness but no peritoneal signs.

Her initial Hgb was 6.6g/dl and subsequently dropped to $5.3 \mathrm{~g} / \mathrm{dl}$ three hours later. She had a normal coagulation profile. Her lactate was $2.0 \mathrm{mmol} / \mathrm{L}$, and lactate dehydrogenase was 1440U/L.

Computed tomography of the chest, abdomen, and pelvis showed bilateral small nodular lung masses up to 4 $\mathrm{mm}$, a $5.2 \mathrm{~cm} \times 4.2 \mathrm{~cm} \times 2.1 \mathrm{~cm}$ mediastinal mass near the thymus, a right hepatic lobe mass measuring 8.7 $\mathrm{cm} \times 8.7 \mathrm{~cm}$, fluid in the right upper quadrant, the hyperdense lesion in the left kidney measuring $5.6 \mathrm{~cm}$, right adrenal nodule measuring $2.6 \mathrm{~cm}$ and scattered enlarged peripancreatic and periportal lymph nodes. There was a large amount of free fluid in the pelvis, multiple omental deposits, and a heterogenous lesion on T11 vertebral body suspicious for metastatic disease (Figures 1 and 2). 


\section{Cureus}

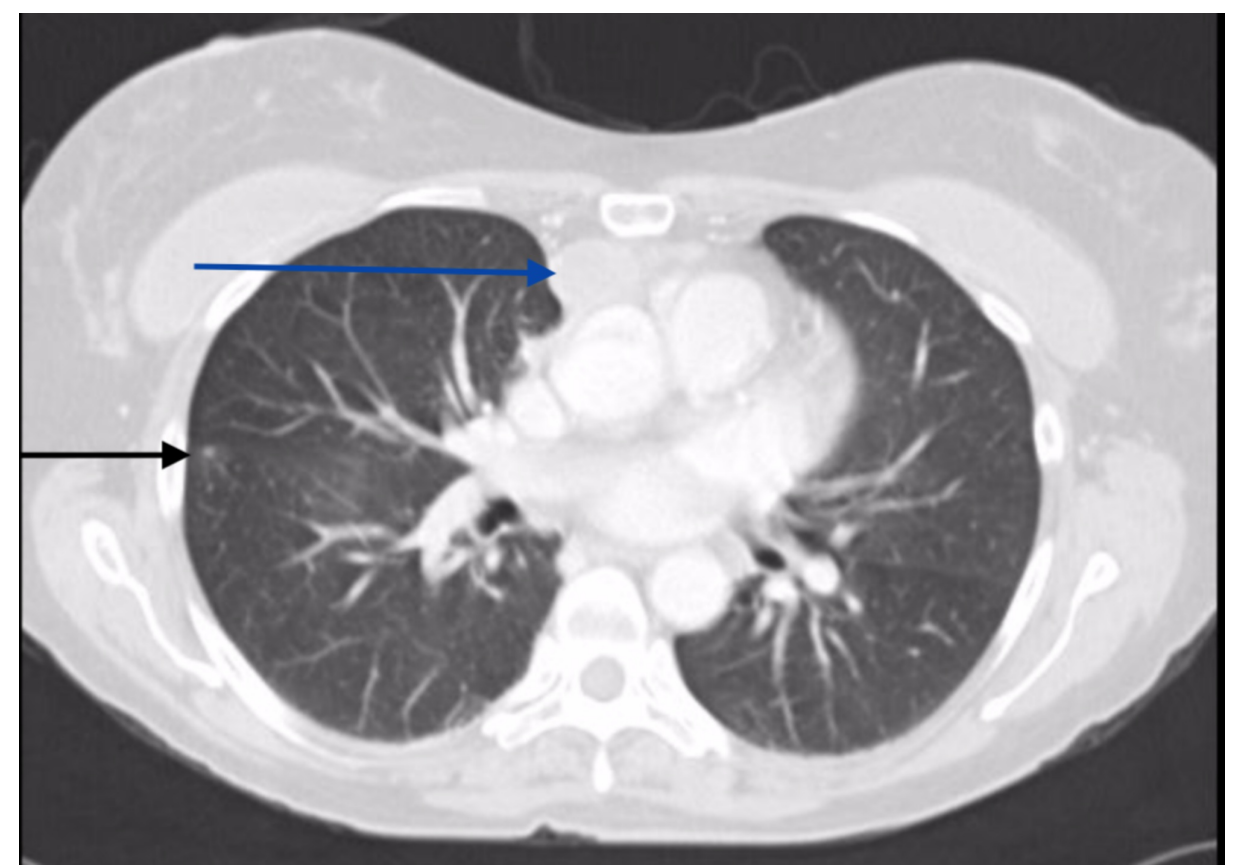

FIGURE 1: Axial chest CT showing right lung lesion

Axial chest CT showing right lung lesion (black arrow) and anterior mediastinal mass (blue arrow). 


\section{Cureus}

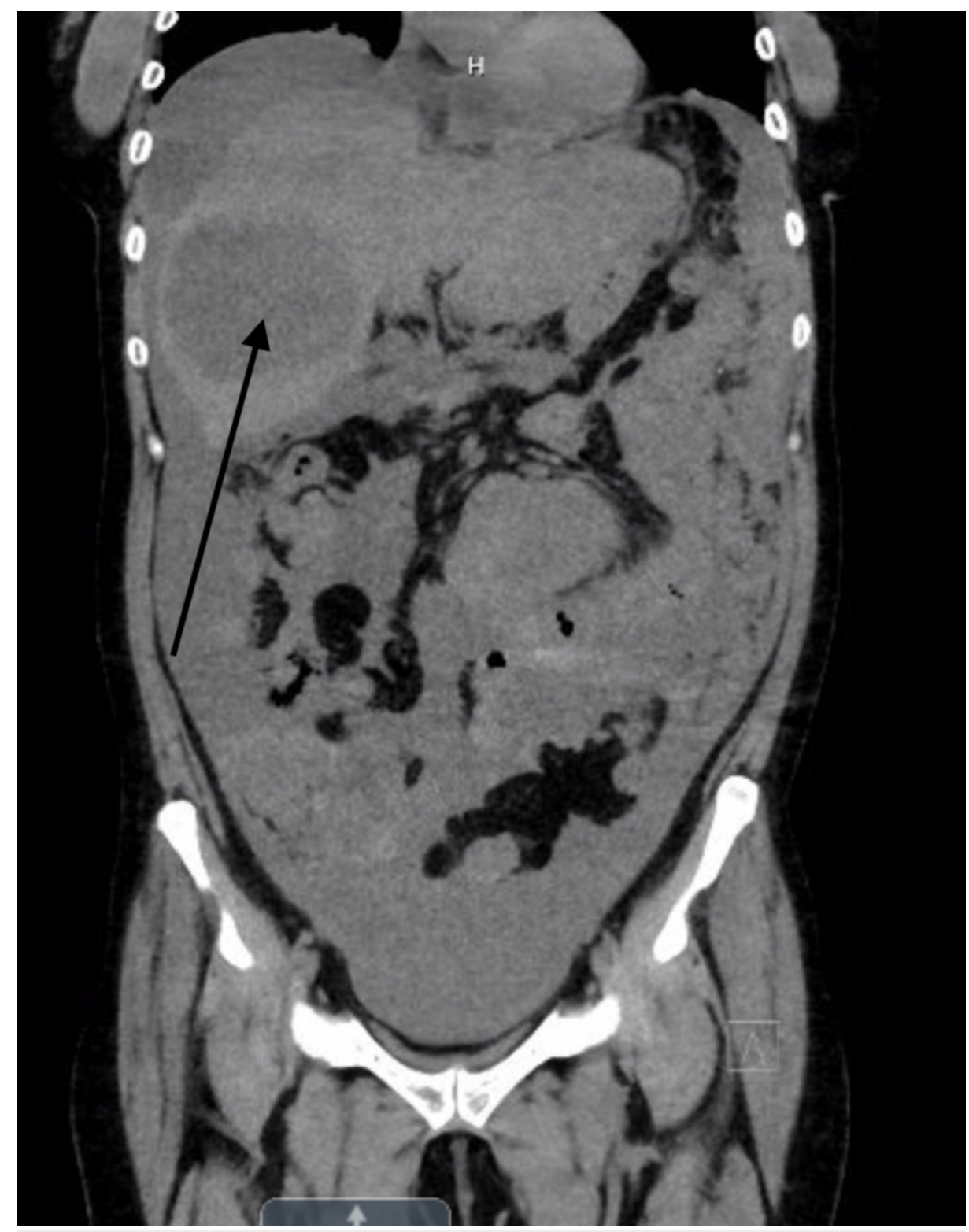

\section{FIGURE 2: Coronal view of CT chest and abdomen}

Coronal view of CT chest and abdomen showing a large right hepatic lobe mass (black arrow) measuring 8.7 $\mathrm{cm} \times 8.7 \mathrm{~cm}$ and fluid in the right upper quadrant.

Tumor markers, including alpha-fetoprotein (AFP), carbohydrate antigen 19-9 (CA 19-9), and carcinoembryonic antigen (CEA) were normal, with an elevated cancer antigen 125 (CA 125) of 186.4 (normal $<35 \mathrm{U} / \mathrm{ml}$ ), stool occult blood was negative.

The patient was transfused two units of packed red blood cells on admission and as needed to keep her Hgb above $8 \mathrm{~g} / \mathrm{dl}$. She underwent ultrasound-guided paracentesis of $2.5 \mathrm{~L}$ of dark hemorrhagic fluid from the abdomen.

Computed tomographic angiography was obtained with the aim to identify the source of the bleed. No active extravasation was seen. Given the ongoing drop in her hemoglobin despite four units of packed red blood cells (PRBC) transfusion and persistent tachycardia, a decision was made to proceed with diagnostic laparoscopy.

Intraoperatively, innumerable friable purple nodules were seen lining both visceral and parietal peritoneum in the intraabdominal cavity as well as the liver, spleen, omentum, and pelvic structures (Figure 3). There was no clearly identifiable source of bleeding observed except for diffuse oozing from the nodules. Due to the diffuse nature of the bleed, we were unable to achieve hemostasis via electrocoagulation or ligation. The absorbable hemostatic powder was placed over lesions that appeared to be oozing. Liver and omental 


\section{Cureus}

biopsies were then obtained for frozen and permanent sections. Frozen sections showed a high-grade anaplastic tumor. A large Jackson Pratt drain was placed. We could not run the bowel due to the matted nature of the small bowel and the likelihood of exacerbating the bleed.

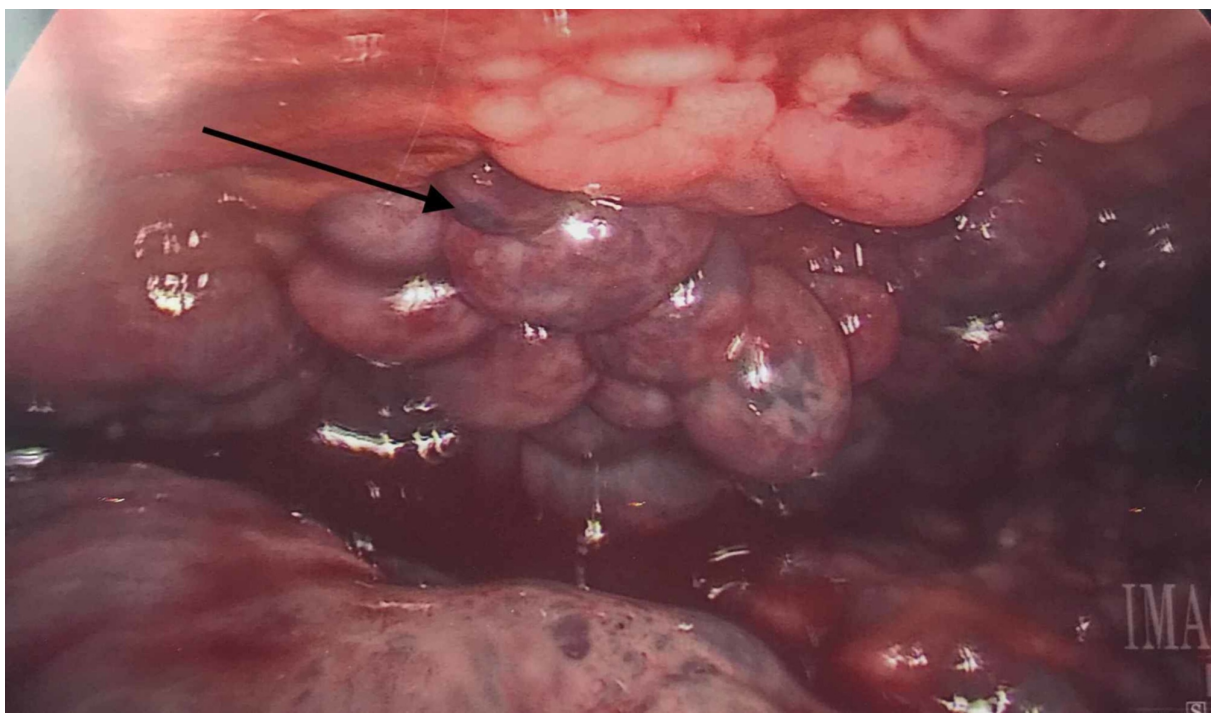

FIGURE 3: Intraoperative pictures showing intraabdominal purplish and friable metastatic deposits of melanoma (black arrow)

Postoperatively, she continued to have significant sanguineous output from the surgical drain. Her final pathology showed round malignant tumor cells, frequent mitoses up to 100 per 10 high power fields. Immunohistochemistry was positive for S100, HMB-45 and MelanA. Molecular studies showed neuroblastoma RAS (NRAS) consistent with melanoma (Figures 4 and 5). Microscopically, the omental tissue was infiltrated by small, round to oval malignant tumor cells with high nuclear-cytoplasmic ratio, punctate or inconspicuous nucleoli, and frequent mitoses up to 100 per 10 high power field. Immunohistochemical stains showed tumor cells positive for S100 (focally), HMB-45 (focally) and MelanA (diffusely). Immunohistochemical stains for CAM5.2, pankeratin, epithelial membrane antigen (EMA), CD45, desmin, smooth muscle actin (SMA), and CD99 were negative in the tumor cells. Molecular studies showed NRAS mutation, which was consistent with the diagnosis of malignant melanoma.

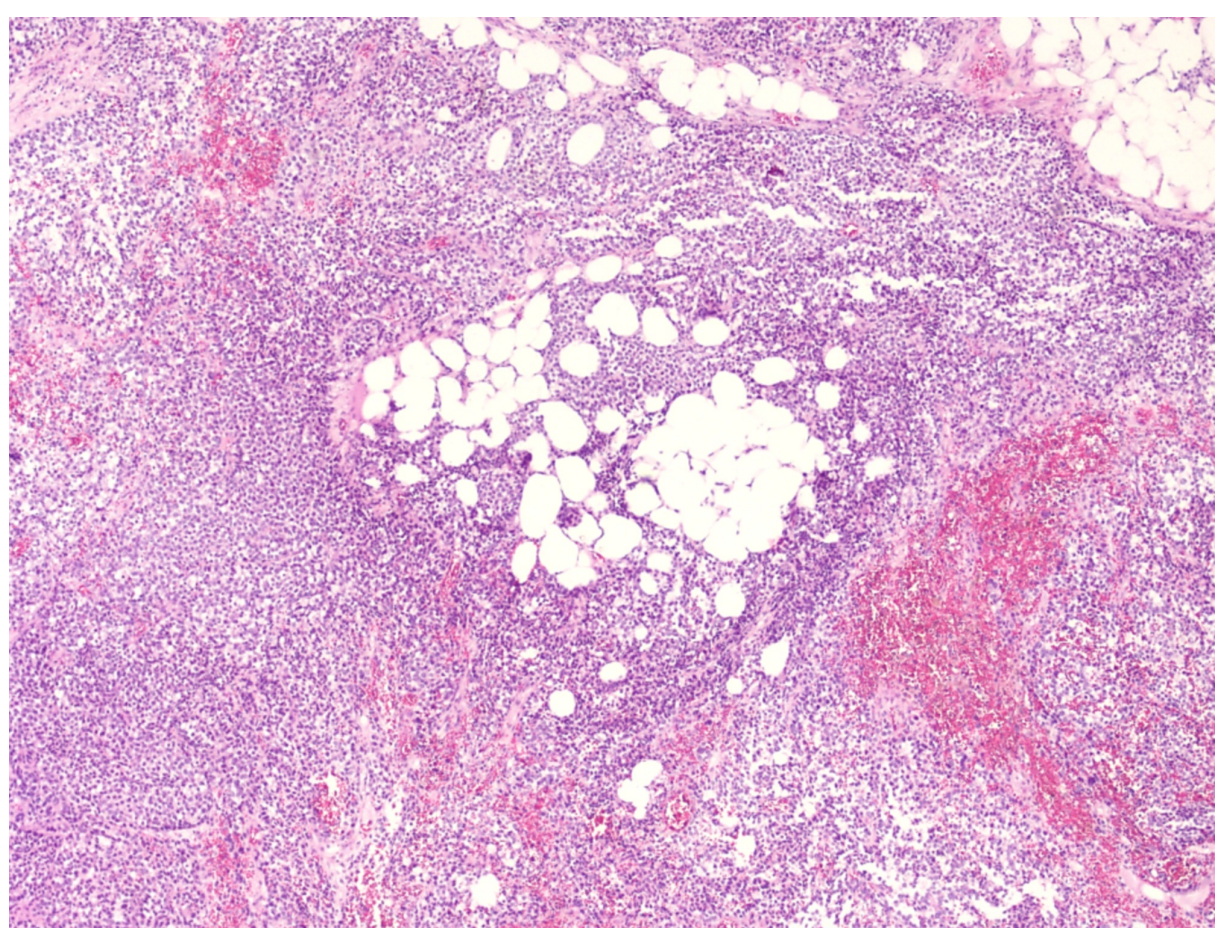

FIGURE 4: Microscopic slides showing H\&E stains (100X) 


\section{Cureus}

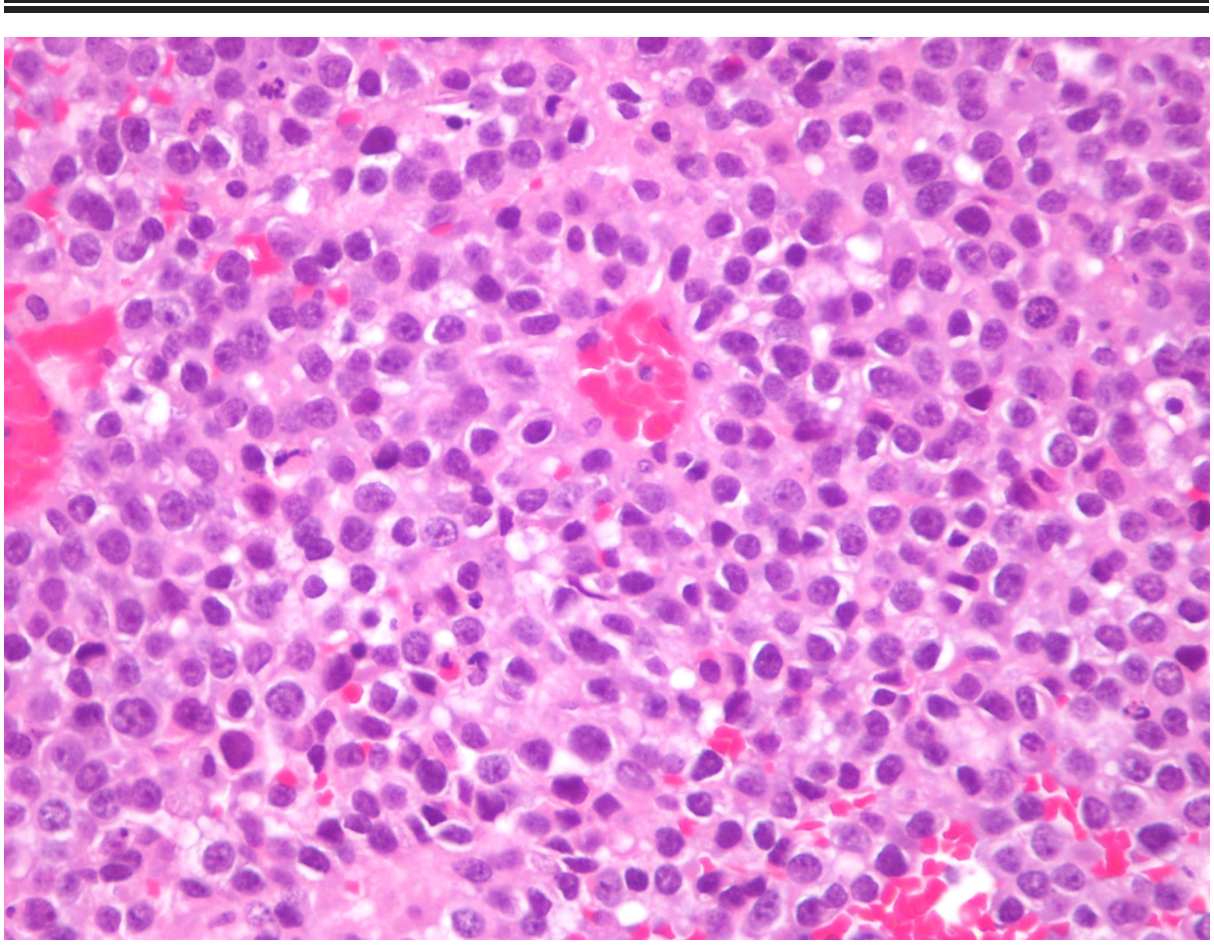

FIGURE 5: Microscopic slide showing H\&E stains (400X)

High power view shows small, round to oval malignant tumor cells with high nuclear-cytoplasmic ratio, punctate or inconspicuous nucleoli and frequent mitoses up to 100 per 10 high-powered field (HPF).

The patient and her family were informed of the poor prognosis of her condition, and options such as enrollment into a clinical trial and palliative care were discussed with the patient; however, they elected to be transferred to a tertiary center to pursue aggressive treatment options where she eventually passed away.

\section{Discussion}

Malignant melanoma is a rare but serious form of skin cancer expected to affect 96,480 persons in the USA in 2019 [1]. Melanoma is aggressive and can metastasize to any organ system [3, 4]. Survival depends on the stage of disease at the time of diagnosis [3]. Early diagnosis with surgical excision can be curative [4]. The most common sites of metastasis are lung, liver, lymph nodes, brain, bone, and gastrointestinal (GI) tract. There are also less common reported metastases to the dura, eye, bile duct, peripheral nerves, uterus, vagina, rectum, and anus [6]. There are very few reported cases of peritoneal carcinomatosis [7]. Additionally, to our knowledge, there is no previous report of melanoma with peritoneal metastasis without a known primary, presenting with hemoperitoneum $[6,7]$.

The reported patient denied any history of skin cancer or any suspicious or new skin lesions. After the establishment of tissue diagnosis, we re-examined the patient for evidence of any cutaneous lesions; however, although we found none, her cutaneous exam was limited due to the patient's inability to cooperate fully in the acute setting. For similar reasons, we were unable to perform aggressive workups, such as an ocular exam, proctoscopy, colonoscopy, or esophagogastroduodenoscopy (EGD) towards identifying the primary tumor. In the ideal setting, a thorough head to toe skin exams is needed, paying particular attention to areas where lesions are commonly missed such as the scalp, ears, axilla, umbilicus, nailbeds and interdigital areas. Examination of the mucosal surfaces such as the oral and vaginal mucosa is also important.

This patient's presentation with nontraumatic hemoperitoneum is also rare. Most hemoperitoneum is secondary to nonmalignant gynecologic conditions. When complicated by malignant disease, hemoperitoneum can present be due to the rupture of liver tumors or other solid organ tumors [8].

The median survival of patients with melanoma with peritoneal metastasis is less than two months [7]. The general approach to the management of metastatic melanoma is multidisciplinary [4]. Surgery can be considered for the oligometastatic disease [2-4]. For advanced metastatic disease, the patient should be 
given the option to enroll in clinical trials [4]. There are ongoing melanoma clinical trials in the USA, aiming to find new and improved treatment options for patients with advanced disease. An example of a multicenter phase III randomized controlled trial (RCT), which is actively recruiting patients, is "A Study of NKTR-214 Combined With Nivolumab vs. Nivolumab Alone in Participants With Previously Untreated Inoperable or Metastatic Melanoma” [9]. Although this patient would have been a good candidate for this trial based on her clinical diagnosis, she may not qualify based on her decreased performance status per the Eastern Cooperative Oncology Group (ECOG) scale of performance status used by many clinical trials as an inclusion criterion [10].

\section{Conclusions}

In conclusion, there is a rising incidence of malignant melanoma. Unusual presentation de novo or as a late recurrence can be expected. Clinicians should be aware of hemoperitoneum or peritoneal carcinomatosis as potential manifestations of malignant melanoma to expedite appropriate management.

\section{Additional Information \\ Disclosures}

Human subjects: Consent was obtained by all participants in this study. Conflicts of interest: In compliance with the ICMJE uniform disclosure form, all authors declare the following: Payment/services info: All authors have declared that no financial support was received from any organization for the submitted work. Financial relationships: All authors have declared that they have no financial relationships at present or within the previous three years with any organizations that might have an interest in the submitted work. Other relationships: All authors have declared that there are no other relationships or activities that could appear to have influenced the submitted work.

\section{Acknowledgements}

We wish to express our deepest gratitude to Iskenda Genco, MD and Sabina Hajiyeva, MD from Northwell Health Lenox Hill Hospital NY, Department of Pathology and Laboratory Medicine for providing us with the pathology report and slides.

\section{References}

1. Siegel RL, Miller KD, Jemal A: Cancer statistics, 2019. CA Cancer J Clin. 2019, 69:7-34. 10.3322/caac.21551

2. Krown SE, Chapman PB: Defining adequate surgery for primary melanoma . N Engl J Med. 2004, 350:823825. 10.1056/NEJMe038235

3. Bhatia S, Tykodi SS, Thompson JA: Treatment of metastatic melanoma: an overview . Oncology. 2009, 23:488-496.

4. Sabiston textbook of surgery; the biological basis of modern surgical practice, 20th edition . Townsend, CM, Beauchamp RD, Evers BM, Mattox KL (ed): Elsevier, Philadelphia; 2017.

5. Ribero S, Moscarella E, Ferrara G, Piana S, Argenziano G, Longo C: Regression in cutaneous melanoma: a comprehensive review from diagnosis to prognosis. J Eur Acad Dermatol Venereol. 2019, 30:2030-2037. $10.1111 /$ jdv.13815

6. Trout AT, Rabinowitz RS, Platt JF, Elsayes KM: Melanoma metastases in the abdomen and pelvis: Frequency and patterns of spread. World J Radiol. 2013, 5:25-32. 10.4329/wjr.v5.i2.25

7. Flanagan M, Solon J, Chang KH, et al.: Peritoneal metastases from extra-abdominal cancer - a populationbased study. Eur J Surg Oncol. 2019, 44:1811-1817. 10.1016/j.ejso.2018.07.049

8. Lucey BC, Varghese JC, Anderson SW, Soto JA: Spontaneous hemoperitoneum: a bloody mess . Emerg Radiol. 2007, 14:65-75. 10.1007/s10140-007-0594-0

9. Sarkisian S, Nair S, Sharma R: Current clinical trials in the treatment of advanced melanomas . Surg Clin North Am. 2020, 100:201-208. 10.1016/j.suc.2019.09.014

10. Oken MM, Creech RH, Tormey DC, et al.: Toxicity and response criteria of the Eastern Cooperative Oncology Group. Am J Clin Oncol. 1982, 5:649-656. 